\title{
Contextos funerarios asociados al Ushnu en el complejo arqueológico de Lumbra, valle medio del río Chancay-Huaral
}

\section{RESUMEN}

En el presente artículo se presenta el hallazgo de contextos funerarios hallados en asociación al ushnu, en el sector B del complejo arqueológico de Lumbra. Este complejo arqueológico, es el único en el valle Chancay-Huaral, donde hasta el momento se ha identificado elementos arquitectónicos Tawantinsuyu, como el ushnu y las dos kanchas, ubicadas frente a la plaza. El hallazgo de estos dos contextos funerarios nos muestra nuevas luces para la comprensión de la ocupación del Tawantinsuyu en el valle medio del río ChancayHuaral.

Palabras Clave: Arqueología; contextos funerarios; Lumbra; valle Chancay-Huaral; Tawantinsuyu; ushnu.

\section{Funeral contexts associated to the Ushnu in the Archaeological Complex of Lumbra, middle valley of the Chancay-Huaral river}

ABSTRACT

The present article presents the finding of funerary contexts found in association with ushnu, in sector B of the archaeological complex of Lumbra. This archaeological complex is the only one in the Chancay-Huaral valley, where Tawantinsuyu architectural elements such as the Ushnu and the two kanchas have been identified in front of the square. The finding of these two funerary contexts shows new insights for the understanding of the Tawantinsuyu occupation in the middle valley of the Chancay-Huaral river.

KeYwords: Archeology; funerary contexts; Lumbra; Chancay-Huaral valley; Tawantinsuyu; ushnu. 
E año 2014 se realizó una temporada de nvestigación en el complejo arqueológico de Lumbra. Esta nueva temporada de investigaciones auspiciada por el Vicerrectorado de Investigación en el marco de los proyectos multidisciplinarios de investigación, tuvo por objetivo el determinar las características de la ocupación del Tawantinsuyu en este importante sitio arqueológico. Para ello, se realizó la excavación de dos unidades en los alrededores del ushnu y otras dos al interior de las dos kanchas. En una de las unidades, la ubicada al oeste del ushnu se halló en la capa $\mathrm{B}$, dos contextos funerarios con los individuos enfardelados, pertenecientes al Horizonte Tardío (Tawantinsuyu).

\section{El complejo arqueológico de Lumbra}

El Complejo Arqueológico de Lumbra se ubica en medio de la quebrada de Lumbra, junto al poblado del mismo nombre, con el punto Datum (WGS-84) en las coordenadas UTM: 8740543N, 0275757E, a $597 \mathrm{~m}$. s. n. m. (Punto tomado en el Sector B), en la margen derecha del río Chancay-Huaral. Políticamente se encuentra ubicado en la localidad de Lumbra, distrito y provincia de Huaral. El complejo abarca una gran extensión de la parte baja de la quebrada.

El complejo arqueológico está conformado por 8 sectores $(\mathrm{A}-\mathrm{H})$, diferenciados entre sí por su organización espacial, componentes arquitectónicos y funcionalidad; así como dos sitios asociados ubicados en el Cerro de Lumbra y en Cerro Gallinazo. Estos sectores son: Sector A: ubicado en la parte baja de la quebrada, en el lado sur del complejo. Está conformado por un sector de función doméstica, ubicado junto a la carretera Huaral-Acos; Sector B: conformado por el sector político administrativo, ubicado inmediatamente al norte del sector A, al otro lado de la carretera; Sector C: conformado por un conjunto de terrazas de función agrícola, ubicadas hacia el norte del Sector B, en medio de la quebrada de Lumbra; Sector D: conformado por un conjunto doméstico ubicado en el lado norte del complejo, en la margen derecha de la quebrada de Lumbra, justo en el cono de deyección, sobre una pequeńa terraza aluvial, circundado por un muro perimétrico que encierra en su interior los recintos de planta cuadrangular y rectangular; Sector E: ubicado en la parte superior del cerro oriental de la parte media de la quebrada, conformado por un conjunto de amplios recintos de planta cuadrangular, de función residencial, de arquitectura más especializada. Los otros sectores son de función de almacenamiento, funerario y ceremonial.

El complejo arqueológico de Lumbra se encuentra rodeado por un complejo sistema de murallas que encierran en su interior, en algunos casos, sectores de forma particular, y en otros a todo el complejo. La muralla más importante es aquella que encierra completamente los sectores $\mathrm{A}$ y $\mathrm{B}$, con dimensiones de hasta $3.50 \mathrm{~m}$ de alto y de 1.50 a $2 \mathrm{~m}$ de ancho.

Son pocos los investigadores que han mencionado, descrito o realizado investigaciones en este importante complejo arqueológico (Agurto y Sandoval; 1974, Horkheimer; 1965, Engel; 1987, Villar; 1982, Krzanowski; 2008: 60-62). En anteriores trabajos hemos presentado las características de cada uno de los sectores (van Dalen; 2004a; 2004b; 2008:61-62; 2009:234-236; 2010a; 2011a; 2013a, 2013b, 2014a, 2014b, 2016a, 2016c, van Dalen, Altamirano, Grados y Castillo; 2013 y van Dalen y Grados; 2014).

\section{El sector B y el ushnu}

El sector B se encuentra ubicado en la parte baja del complejo, al norte del sector A, al otro lado de la carretera. Está conformado por un conjunto de estructuras de función político-administrativo $y$ ceremonial, que se constituiría en el área nuclear del asentamiento, con evidencias de constantes remodelaciones en el Intermedio Tardío y en el Horizonte Tardío (van Dalen; 2013b).

Entre las estructuras del Intermedio Tardío destaca una plataforma elevada de planta semicuadrangular, posiblemente con rampa frontal (aún no definida, pero inferimos que lo tenga por el patrón de estas estructuras en el valle), con muros de contención a base de piedras canteadas, cantos rodados y adobes, de 3 metros de altura (sin contar las estructuras superpuestas del Horizonte Tardío). Esta estructura se encuentra orientada en un eje noroeste-sureste, tiene 30 metros en su eje suroeste-noreste por 28 metros en su eje noroeste-sureste, y está asociada en la parte frontal a un patio rectangular, y este a su vez a un conjunto de recintos rectangulares. La estructura no es exactamente cuadrada, presenta algunos muros de contención zigzagueantes. 


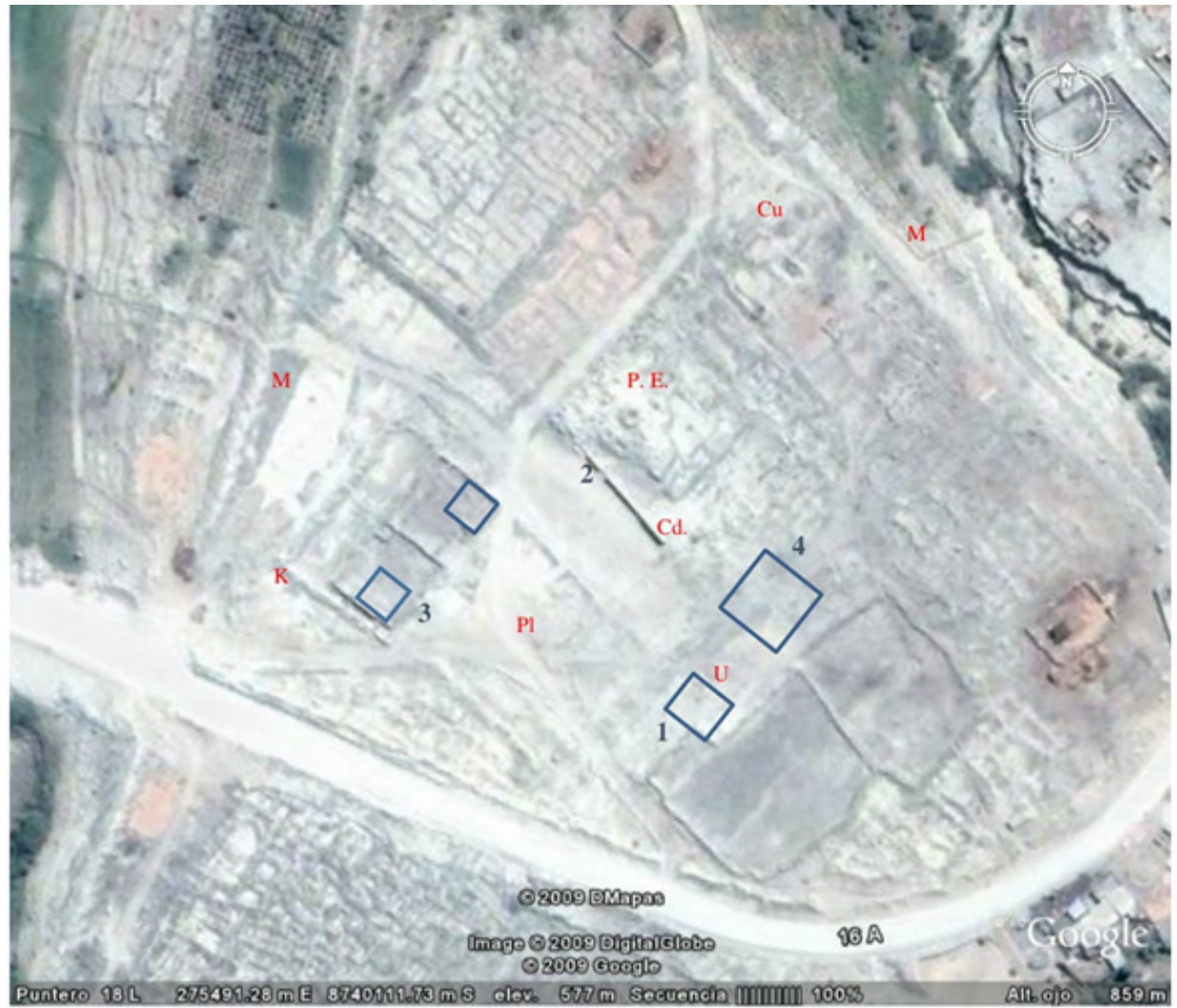

Figura 1: Foto satelital del sector $B$ del complejo arqueológico de Lumbra con la ubicación de los principales componentes arquitectónicos del Horizonte Tardío y en azul las unidades de excavación de la temporada 2014 entre estas la unidad 1 junto al ushnu donde se recuperó los dos contextos funerarios. Leyenda: K: Kanchas. P. E.: Plataforma Elevada. Pl.: Plaza. U: Ushnu. Cd.: Cuadrilátero. M: Muralla 1. Cu: Cúpula.

En el lado Oriental del sector, cuyo límite natural es el acantilado del cauce de la quebrada de 8 y 10 metros de profundidad, en cuyo borde pasa la primera muralla perimétrica, se encuentran un conjunto de habitáculos, de función no definida, y entre estos existen dos cúpulas medianas, piedras con numerosos orificios con posibles fines astronómicos. La de mayores dimensiones presenta más de 30 orificios circulares de hasta $1 \mathrm{~cm}$ de profundidad.

Durante el Horizonte Tardío se nota una gran variación en la organización espacial del sector. La plataforma elevada y los recintos aledaños, fueron encerrados en un gran cuadrilátero de planta cuadrangular, con muros perimétricos hechos a base de tapias, mediante la técnica de pańos murarios. Los muros presentan un perfil trapezoidal, con hasta cuatro niveles de paños superpuestos, enlucidos en su totalidad con una gruesa capa de barro. En todos los casos los paramentos externos están inclinados hacia dentro, mientras que los paramentos internos son verticales. Hacia el lado suroeste, la plataforma elevada ha sido ampliada, aparentemente después de la construcción del muro perimétrico, dándole además mayor altitud, con la edificación de un conjunto de recintos de planta cuadrangular en la parte superior hechos a base de tapiales. El acceso al cuadrilátero se ubica en la parte frontal, hacia el sureste.

Hacia el lado suroeste del cuadrilátero se ubica una gran plaza de forma cuadrangular, asociada al cuadrilátero, a un conjunto de dos kanchas y a un pequeño ushnu. La plaza tiene 82 metros en su eje noroeste-sureste, por 66 metros en su eje suroestenoreste. Se aprecia en medio alineamientos de piedras, que habrían conformado las bases de muros dobles, destruidos para la habilitación de la plaza.

Hacia el lado sureste, se ubica una pequeńa plataforma de 2.90 metros (eje suroeste-noreste) por 3.00 metros (eje noroeste-sureste), con una altitud de 1.40 metros de altura. Esta plataforma, por sus características pecualiares y su asociación, se trata de un ushnu pequeño, edificado con muros de contención de 0.35 metros de ancho, a base de piedras canteadas grandes. En la parte posterior, el ushnu está adosado a un muro de piedras canteadas que delimita la plaza por el lado sureste. El año 2008 se halló frente al ushnu vasijas rotas que formaban parte de la ofrenda pre-constructiva (Ibid; 2016a: 153-155); mientras que el año 2012 se recuperó dos quipus hacia el lado este (van Dalen; 2016a: 212215, van Dalen y Grados; 2014). 
Hacia el otro lado de la plaza, frente al Ushnu, se encuentra un conjunto de dos kanchas, adosadas y asociadas a un gran corral en el lado posterior. La primera kancha se ubica en el lado noreste, está conformado por 5 recintos rectangulares, de entre 2.00 y 3.45 metros de ancho, dispuestos consecutivamente alrededor de un patio de 12.20 metros por 16.00 metros. Los muros están edificados a base de piedras canteadas de regular tamaño, unidos con argamasa de barro. El acceso a esta kancha se realiza por el lado izquierdo. La otra kancha está conformada por seis recintos rectangulares de 3.50 metros de ancho en promedio, dispuestos alrededor de un patio cuadrangular de 13.50 metros (promedio) por 12.00 metros, con muros de la misma tecnología constructiva que el anterior. En la parte posterior de las dos kanchas existe un recinto rectangular de gran tamaño, de

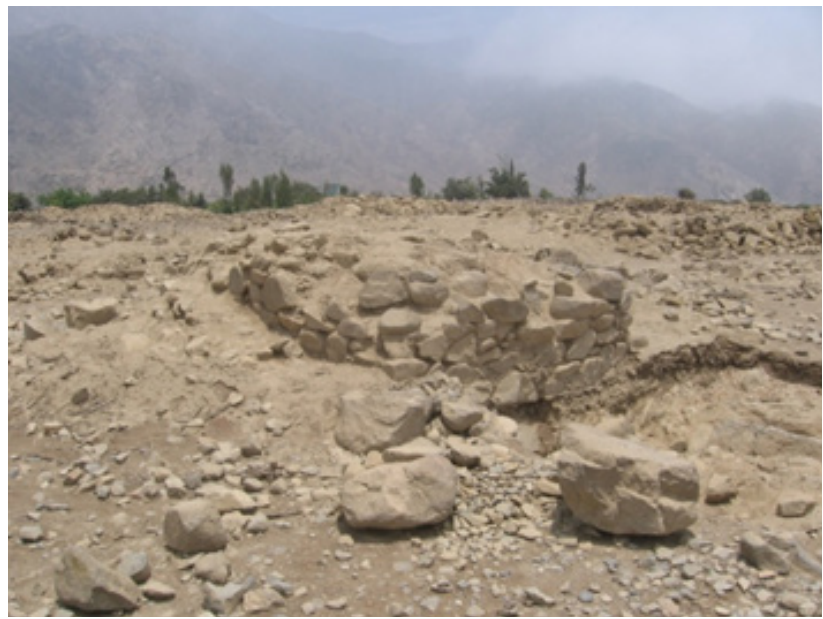

Figura 2 (izquierda): vista panorámica del ushnu.

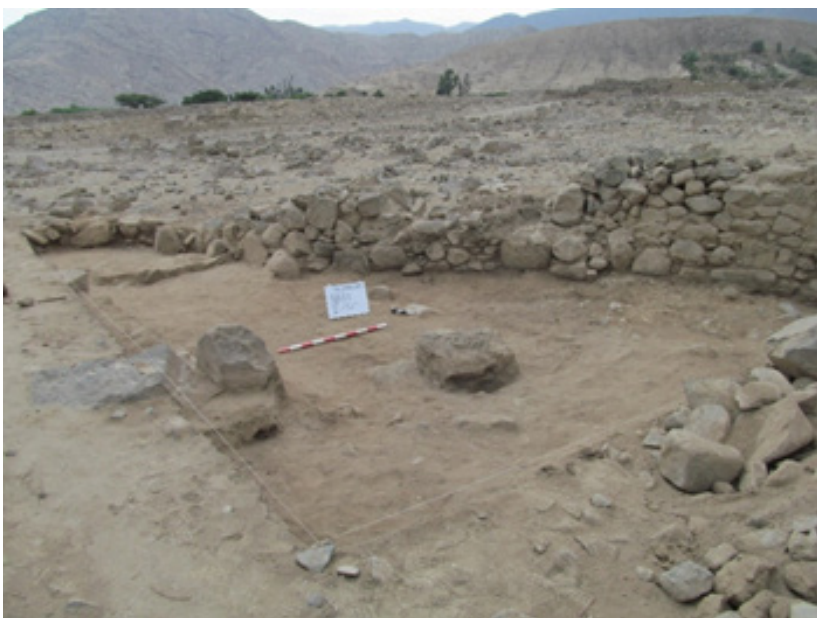

Figura 4 (izquierda): vista del muro 1 adosado al ushnu.
47 metros de largo, por 14.70 metros de ancho, al cual se accede por un pasadizo que discurre junto a la kancha 2, por su lado suroeste.

En la parte frontal de las kanchas, frente al acceso de la kancha 1 , se aprecian los restos de una pequeña plataforma, alineado frontalmente con el ushnu, por lo que pensamos que podría tratarse de otro ushnu, ubicado al otro lado de la plaza, pero lamentablemente en muy mal estado de conservación.

\section{Los contextos funerarios asociados al ushnu de Lumbra}

Los contextos funerarios se recuperaron en la unidad de excavación 1 , ubicada a inmediatamente al suroeste del ushnu, junto a este. Se trata de una unidad de $8 \mathrm{x}$ 8 metros. La unidad presentaba un muro (de norte a

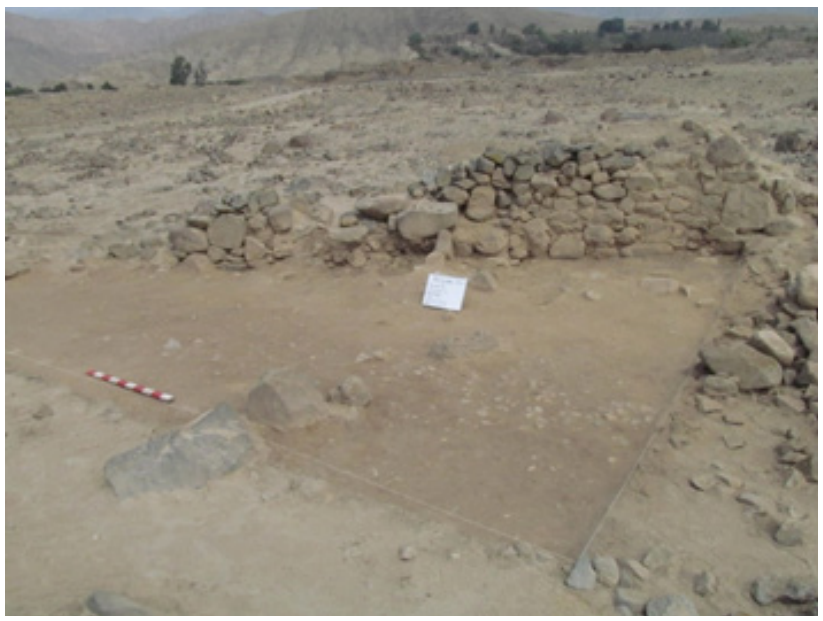

Figura 3 (derecha): Vista de la capa B de la unidad 1.

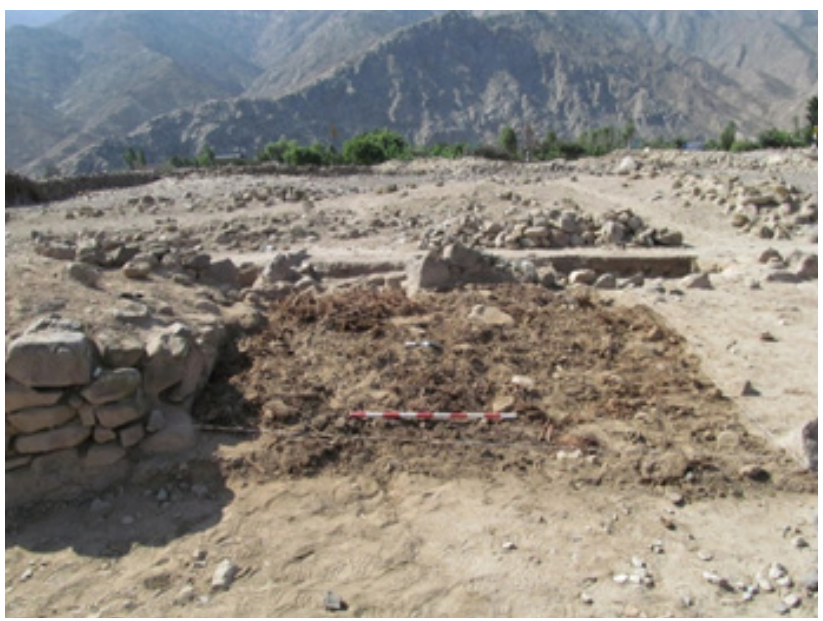

Figura 5 (derecha): vista de la capa A de la subunidad I, nótese el material vegetal rellenado. 
sur), que divide la unidad en dos subunidades (lado este: $30 \mathrm{~m}^{2}$ y lado suroeste: $22 \mathrm{~m}^{2}$ ).

La secuencia estratigráfica identificada en la subunidad I (lado este) fue la siguiente:

Capa superficial: Capa producto de acción eólica y antrópica, de coloración gris, consistencia suelta, compuesta por arenilla, con inclusiones de piedras canteadas, producto del colapso de muros contiguos. Presenta un grosor entre 0.03 metros y 0.10 metros.

Capa A: De consistencia semicompacta, compuesta por el derrumbe del ushnu, el cual se compone de piedras canteadas, con diámetros entre 0.50 metros y 0.30 metros. La capa tiene un grosor entre 0.10 metros y 0.30 metros, de coloración beige oscuro. En la interfacie inferior se encontró un lente de ceniza (en el lado colindante al ushnu) el cual se extiende 0.60 metros al este de la unidad.

Capa B: Capa de consistencia semicompacta, coloración beige oscura, compuesta por arena y gravilla. Presenta material cultural: fragmentería cerámica y óseo animal, con mayor frecuencia frente al ushnu. Presenta un grosor de entre 0.10 metros y 0.25 metros.

Capa C: Frente al ushnu, la capa de color beige se compone de cascajo y gravilla entremezclado con tierra, elaborado para nivelar el terreno sobre la roca madre (capa D). En el centro de la subunidad, se observa la base de un muro (muro 2) que va de sur a norte (anterior al ushnu y correspondiente al Intermedio Tardío), compuesto solo por una hilera de piedras canteadas y adobe. Este muro se asienta en la capa C. En el lado sur se observa la base de otro muro doble cara (muro 3), edificado con piedras canteadas (de 0.80 metros de ancho y un largo de 2.20 metros) unidas con argamasa de barro. Esta capa no presenta materiales culturales muebles y se asienta sobre la capa geológica (capa D).

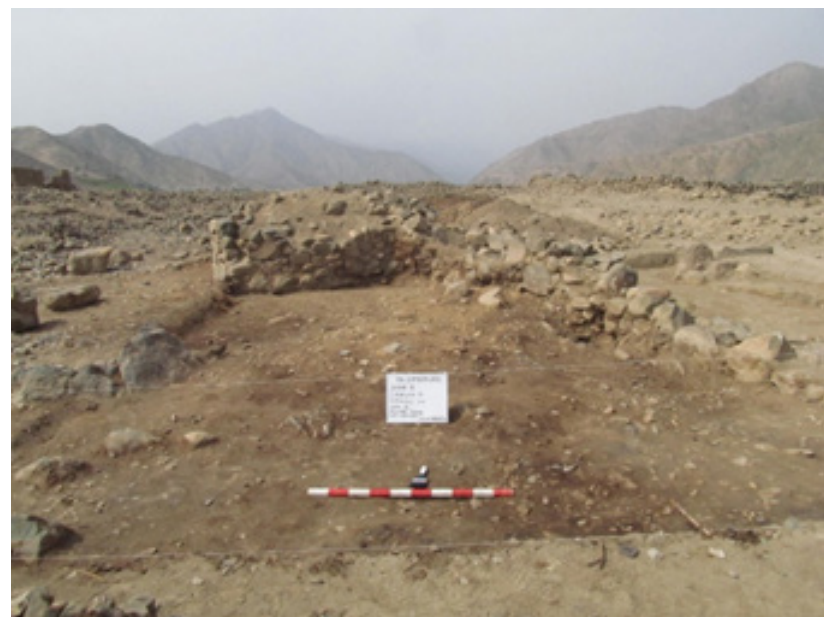

Figura 6 (izquierda): vista de la superficie de la capa B (Subunidad II).
La secuencia estratigráfica en la subunidad II (lado suroeste, hacia el lado de la plaza) es la siguiente:

Capa superficial: La misma que en la subunidad I, de entre 0.03 a 0.10 metros de grosor. Se observa un desnivel de este a oeste.

Capa A: Está conformada por una capa de desechos orgánicos (compuesta por carrizos, semillas de frijol, lúcuma, pacae, zapallo, tuza de maíz, mates, plumas, cabello, algodón), fragmentos cerámicos (de estilo Chancay Llano y Chancay base crema), retazos textiles, soguillas, óseos animal y humano. La capa varía en grosor entre los 0.10 metros y los 0.45 metros Entre los 0.15 metros y los 0.30 metros de profundidad se halló piedras canteadas, producto del colapso de muros (muro 1 y ushnu). La capa tiene coloración marrón y consistencia semicompacta.

Capa B: De consistencia semicompacta, compuesta por un relleno mezclado de graba y tierra, colindante al muro 1. Es de mayor consistencia, asemejándose a una mezcla de argamasa poco consistente. Esta capa es inexistente frente al ushnu, y va engrosando conforme se aleja de este. Hacia el lado este, presenta escaso material cultural. Al interior de esta capa se hallaron dos contextos funerarios colindantes, cuyas matrices estaban elaboradas dentro de esta capa. El grosor de esta capa no es uniforme, pudiendo llegar a tener hasta 0.50 metros de profundidad, y desapareciendo junto al ushnu.

\section{Contextos funerarios:}

Se identificaron dos contextos funerarios, ubicados junto al muro 1, cuyas matrices funerarias se encuentran intruidos en la capa B.

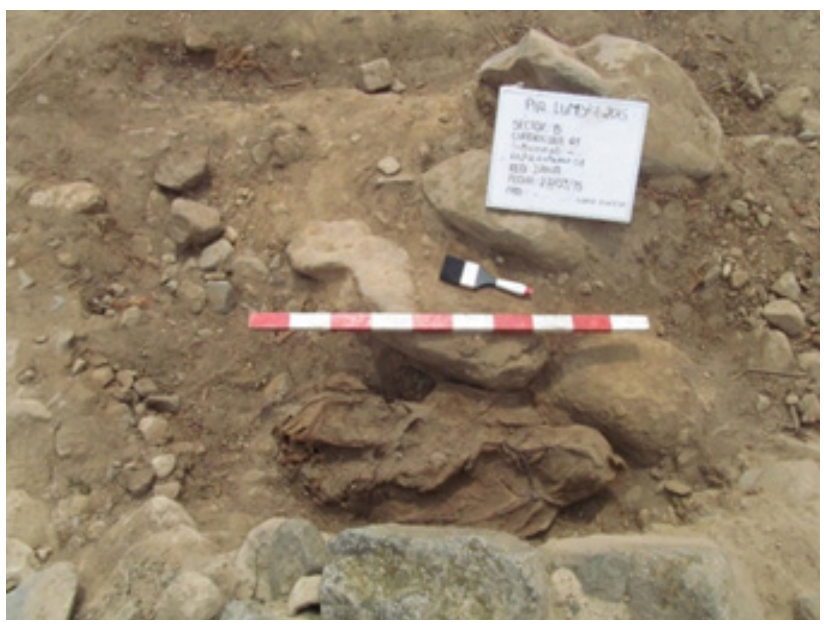

Figura 7 (derecha): Vista panorámica del contexto funerario 1. 


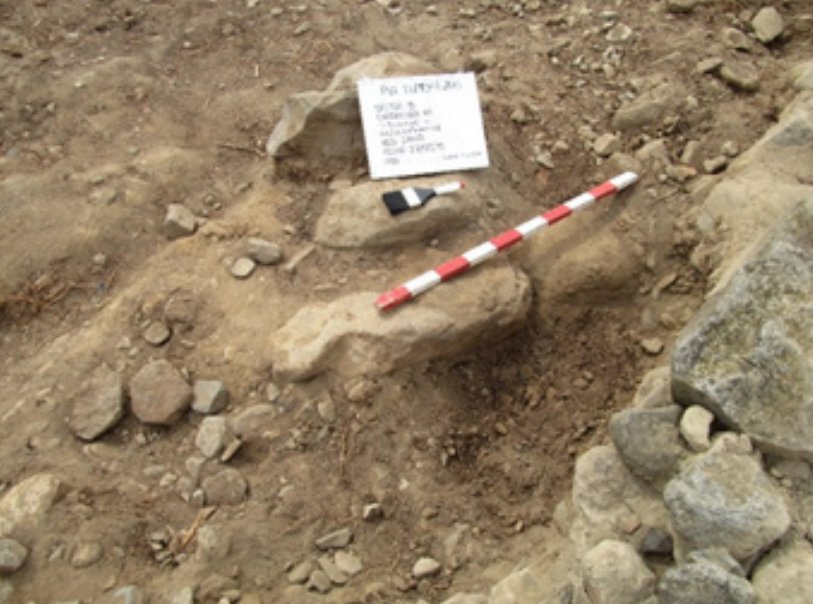

Figura 8 (izquierda): vista de la matriz del contexto funerario 1.

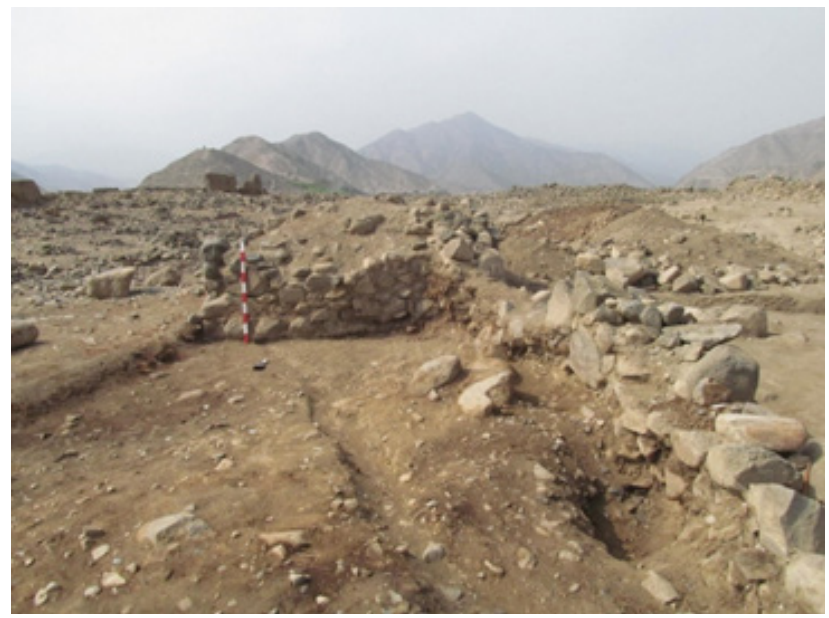

Figura 10 (izquierda): vista panorámica del canal que recorre la parte central de la subunidad II.

Contexto funerario 1: Contexto funerario individual, con el individuo colocado al interior de un fardo, en posición extendida, con orientación noroeste, a 2.60 metros (al suroeste) del ushnu, con el muro 1 hacia el lado sureste. La estructura funeraria está conformada por una matriz, de planta irregular, de 1.10 metros de largo (eje norte-sur) por 0.70 metros de ancho (eje este-oeste) y una profundidad de 0.35 metros. La estructura funeraria está delimitada por dos piedras de gran tamaño (la del lado este tiene un diámetro de 0.60 metros). No se encontraron elementos asociados al individuo. No presenta alteración antrópica, hallado en su contexto original. La matriz estuvo cubierta por relleno de tierra semicompacta. La estructura funeraria se intruye a la capa $\mathrm{B}$, a una profundidad de 0.41 metros, de la superficie.

Contexto funerario 2: Contexto funerario individual. La estructura funeraria es una matriz de

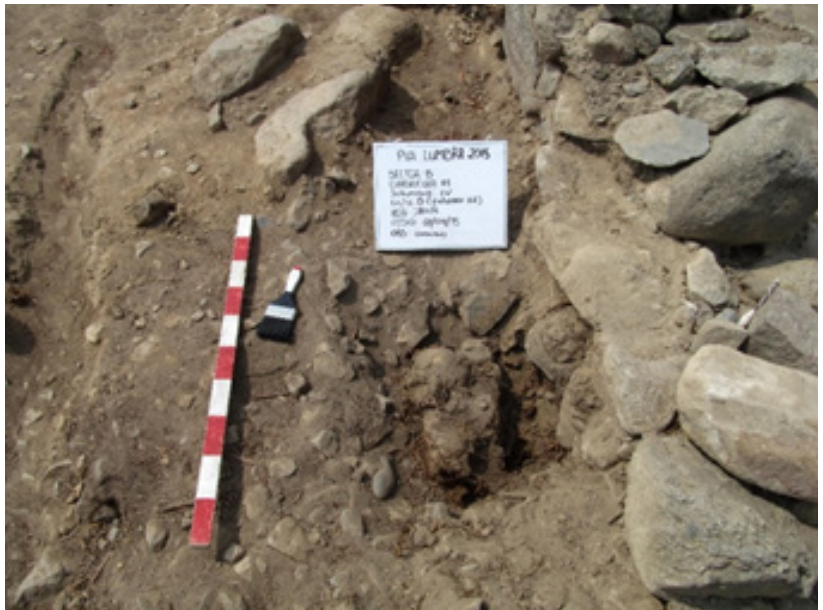

Figura 9 (derecha): vista del contexto funerario 2.

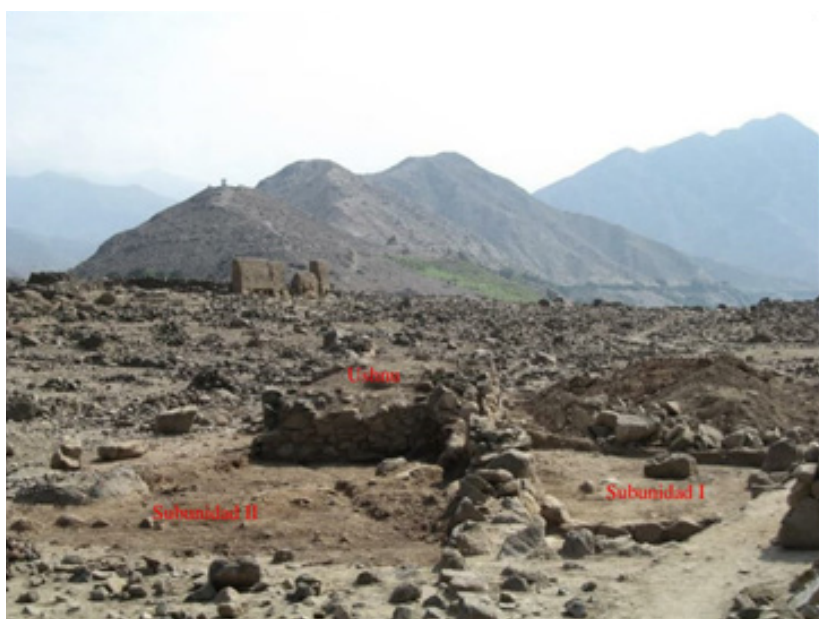

Figura 11 (derecha): Vista panorámica de la unidad al finalizar la excavación, con la ubicación de las dos subunidades y el ushnu detrás.

planta ovalada, de 0.50 metros de diámetro y una profundidad de 0.30 metros $\mathrm{El}$ individuo se encuentra colocado al interior de un fardo en posición flexionada, orientado al noreste. El muro 1 es el límite este de su matriz. No presenta alteración antrópica, se halló en su contexto de deposición original. No presenta elementos asociados. Al igual que el otro contexto, se intruye en la capa $B$, a una profundidad de $0.40 \mathrm{~m}$. de la superficie.

Canal: Excavado sobre la tierra, rellenado por la capa $B$, el cual tiene inicio en el extremo noroeste del ushnu en dirección sureste. Tiene un ancho máximo de 0.20 metros, un largo de 4 metros, discurriendo por toda la subunidad hasta el extremo sur. Tiene una profundidad máxima de 0.09 metros. Este canal servía para desaguar y drenar los líquidos del interior del ushnu.

Capa C: Está conformada por roca angulosa de regular tamaño (entre 0.25 metros y 0.40 metros). 
En el lado sureste de la subunidad se puede observar el afloramiento rocoso geológico. Posee un grosor de entre 0.10 metros y 0.60 metros. Tiene coloración beige y consistencia semicompacta. Sobre esta capa se asentó las bases del ushnu.

Muro 1: Está adosado al ushnu, edificado con piedras canteadas medianas mampuestas con argamasa. Tiene un largo de 8.30 metros, una altura máxima de 0.90 metros y un grosor de 0.60 metros. En tiempos contemporáneos se ha colocado dos hileras de piedras para habilitar corrales de ganado vacuno y caprino. El basamento se asienta sobre la capa $\mathrm{C}$, que es la misma que la capa D de la subunidad I.

\section{Análisis de los contextos funerarios}

Contexto funerario 1. Se trata de un fardo funerario de 0.95 metros de largo por 0.49 metros de ancho. Contexto primario, el individuo se encuentra al
Figura 12 (izquierda): Fardo 1 de individuo masculino adulto. Figura 13 (derecha): vista de la apertura del Fardo 1.
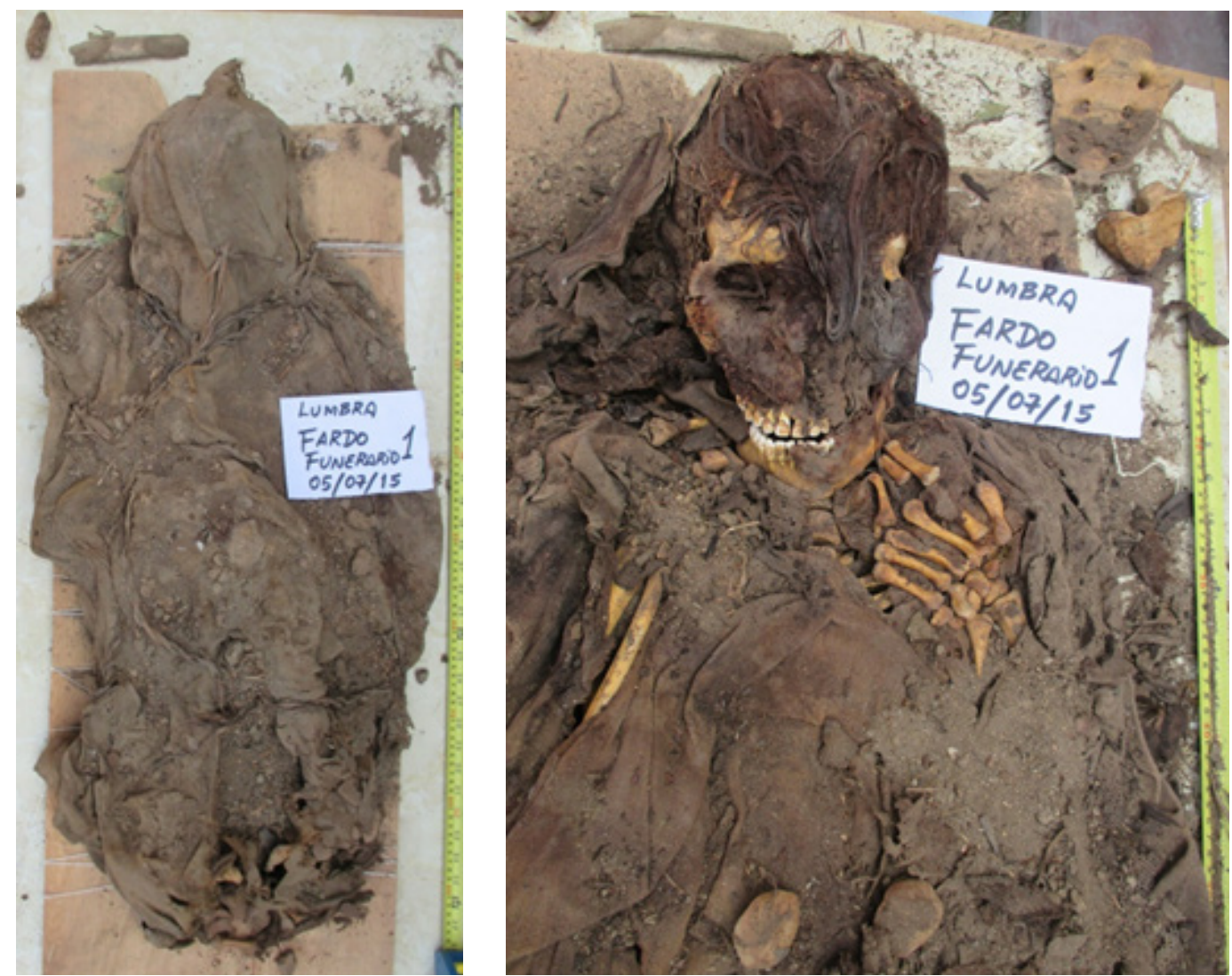
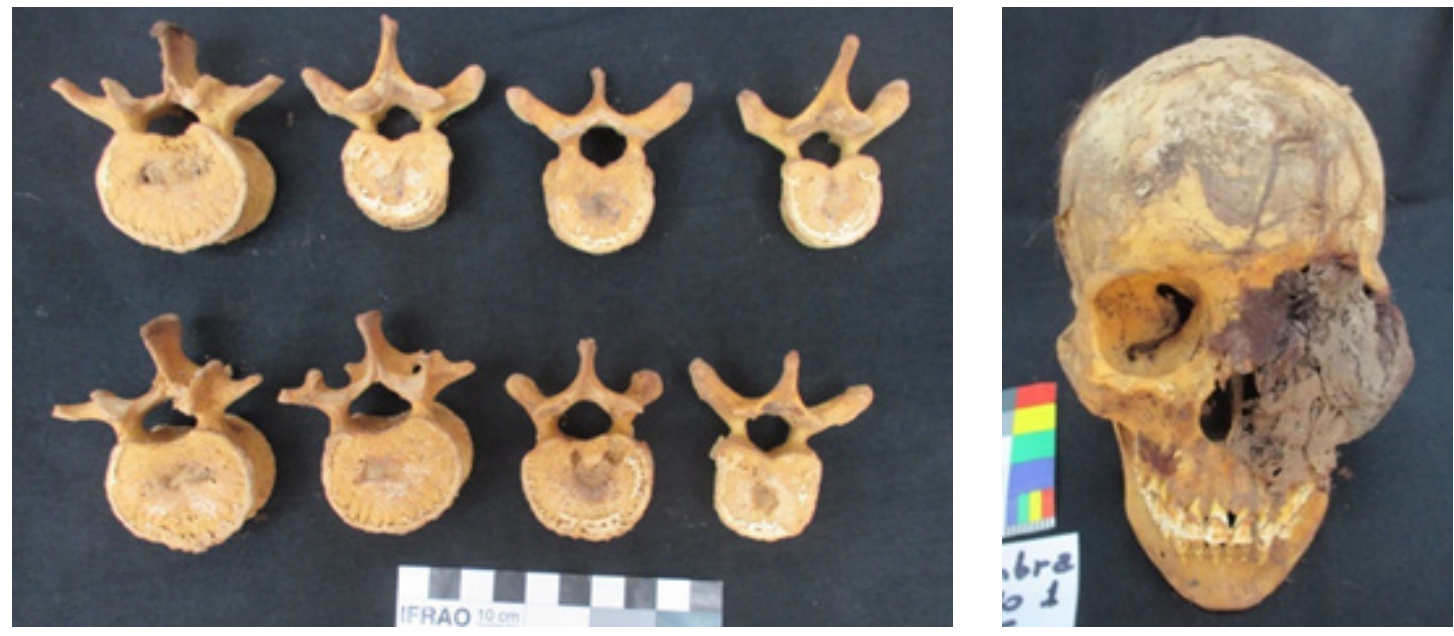

Figura 14

(izquierda): vértebras torácicas y lumbares con d.d. de tuberculosis fardo 1. Figura 15 (derecha): Cráneo del individuo masculino del fardo 1. 

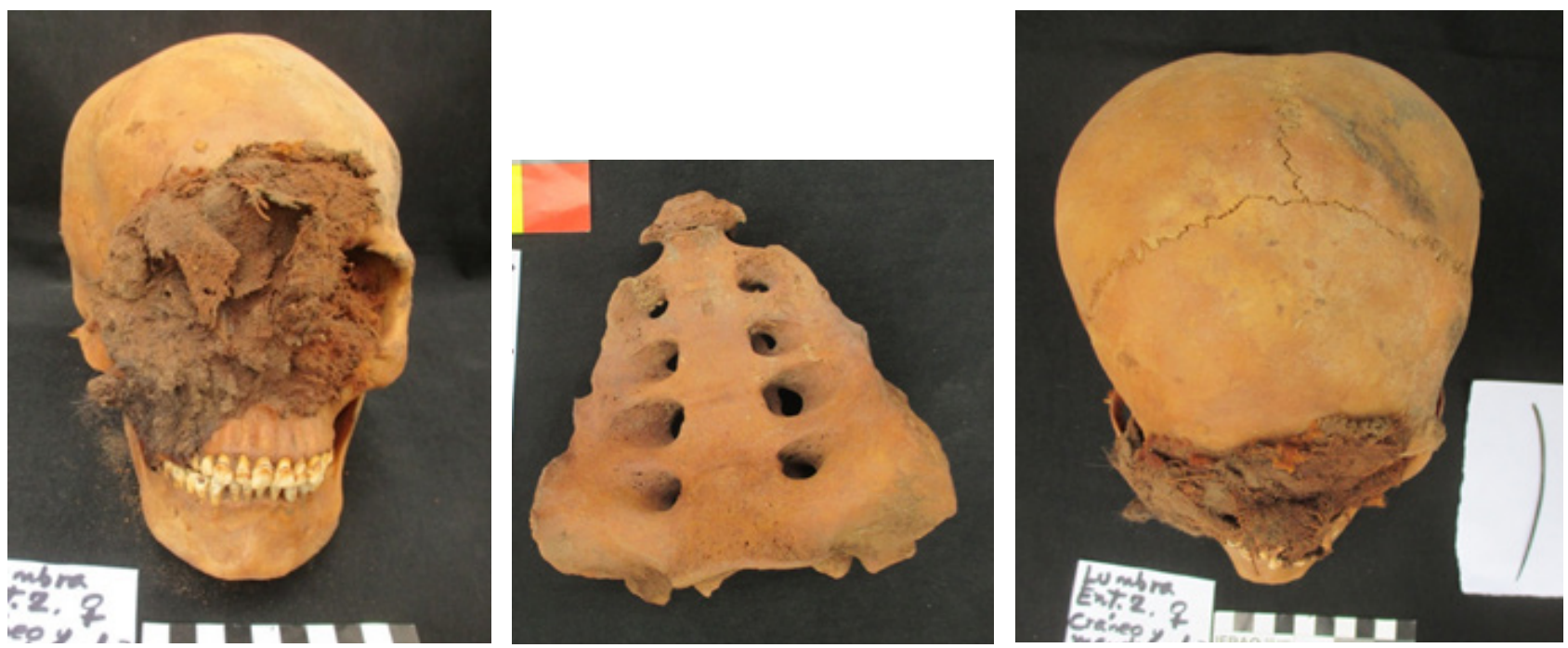

Figura 16 (izquierda): Cráneo del individuo femenino joven del fardo 2, con textil adherido al rostro. Figura 17 (centro): Sacro del individuo femenino con sacralización coccígea. Figura 18 (derecha): Cráneo norma superior del individuo femenino con una aguja de cobre.

interior del fardo en posición decúbito dorsal, con brazos y piernas flexionadas. El fardo está conformado por un envoltorio textil de algodón marrón o fifo (Gossypium barbadense), elaborado en técnica $1 x 1$ torzal, con soguillas atadas externamente a la altura del cuello, del tórax y abdomen. Poseía dos envoltorios, uno tosco externo o abasca (textil 1) y otro fino o gasa adherida al cuerpo de color marrón (textil 2). En el pecho había un tejido anudado formando una simbología de "X». Los brazos y manos estaban próximos al rostro y en la boca tenía motas de algodón marrón, con coágulos sanguíneos. Se trata de un individuo masculino de entre 18 a 22 ańos de edad, con abundante cabello negro y con $\mathrm{HV}$ (Hipervacularización) en la articulación coxofemoral y en los tobillos.

Diagnóstico diferencial (D. D.) de muerte: TBC (Tuberculosis). El cuerpo se halló completo. Presenta las vértebras torácicas: T8, T9, T10, T11, T12, L1, L2, L3, con pequeñas fosas desgastadas en los cuerpos vertebrales, tanto en las caras anteriores como posteriores. La estatura del individuo era de 1.61 metros.

El individuo estaba asociado (dentro del fardo) a fragmentos de cerámica Chancay-Inca o Inca local con tuza de maíz (Zea mays), un húmero de cuy (Cavia porcellus) y una costilla de camélido doméstico.

Contexto funerario 2. Fardo funerario de 0.55 metros de largo por 0.44 metros de ancho y 0.36 metros de grosor, con el individuo depositado en posición sedente, con dos envoltorios textiles de color marrón o fifo (Gossypium barbadense), con bandas azules, de algodón, elaborado en técnica simple de 1 x 1; con soguillas anudadas al cráneo. Se trata de un individuo completo femenino de 18 ańos de edad. Tenía un textil con un nudo trenzado a la altura del pecho. Tenía una aguja de cobre (de $9 \mathrm{~cm}$ de largo) en la mano derecha, ligeramente arqueada. Presenta HV (Hipervacularización) en la epífisis proximal del húmero, en la epífisis distal de radio y en los codos, así como HV en la articulación coxo-femoral. Tenía una altura de 1.42 metros.

El rostro estaba adherido con restos de textil fino y cabellos humano. El sacro presenta sacralización coxígea. Tuvo 5 hijos o más. Presenta caries en el tercer molar inferior derecho. Por el desgaste dentario, de superficie marrón a pardo, se infiere que esta mujer de cuerpo robusto, chacchaba hojas de coca para aliviar el dolor de la muela.

El cráneo presenta fuerte modelación tabular oblicuo con achatamiento de la pared derecha, con 2 líneas en el cráneo parietal derecho, lo que indica su posible afinidad genética con grupos altoandinos, como los Atavillos o Huarochirí. Además, presenta hiperostosis porótica en los parietales posteriores. Los dientes están en perfecto estado de conservación, los incisivos centrales son del tipo pala. Además, expone un fuerte golpe en la parte superior izquierda de la cresta nucal, lo que habría sido la causa de muerte. 


\section{Caracterización de los contextos funerarios de lumbra en el contexto del horizonte tardío en el valle y en el sitio}

Son pocos los reportes sobre hallazgos de contextos funerarios de la cultura Chancay. El primero en describir las características de los cementerios de la cultura Chancay fue Julio C. Tello (2015), tanto en Huando, Jecuán, como en el valle de Huaura. Posteriormente, Hans Horkheimer (1965, 1970) describe las características de numerosos cementerios de los valles de Chancay y Huaura, entre estos los de Lauri, Macatón, Teatino, Jecuán, Cementerio de Cuyo, Cementerio de Pasamayo, Cementerio de Quebrada Huaquería, entre otros; llegando a excavar numerosos contextos funerarios en Lauri. Rosa Fung (1960) describió el hallazgo de una tumba Chancay saqueada en el sitio arqueológico de Macatón, evidenciando los numerosos materiales asociados al individuo. Hilda Vidal (1969), reportó el hallazgo de 22 contextos funerarios en los trabajos de ampliación de la carretera Panamericana en Pasamayo. En la década de 1970, Agurto Calvo y Alfredo Sandoval (1974) desarrollaron el catastro e inventario de sitios arqueológicos del valle Chancay, registrando más de cincuenta cementerios. Miguel Cornejo (1985, 1991, 1992, 1999), realizó el análisis de 18 contextos funerarios excavados por Hans Horkheimer en Lauri, a partir de los cuales, plantea una importante secuencia cronológica y seis tipos de tumbas. Andrzej Krzanowski (1991, 2008) registró numerosos cementerios Chancay, asociados a centros administrativos. Pieter van Dalen (2013c) recuperó 21 contextos funerarios del sitio arqueológico de Macatón, cinco de ellos en contexto de deposición original. El mismo autor, reportó el hallazgo de dos contextos funerarios en el sitio de Pampa de Animas La Wasa (van Dalen, 2012), así como el contexto funerario de una tejedora del sitio de Hualmay (van Dalen; 2010b); ambos sitios en el valle de Huaura. Entre los años 2014 y 2017, van Dalen y su equipo de investigadores desarrollaron excavaciones intensivas en el área funeraria de Cerro Colorado, valle de Huaura, logrando recuperar cerca de dos millares de contextos funerarios de la cultura Chancay, información que aún está en procesamiento de datos (van Dalen, Grados, Tello, Vivanco, Flores y Marcelo; 2014, van Dalen y Carbonel; 2015, van Dalen, Tello y Grados; 2016, van Dalen; 2017). De igual manera, es importante el trabajo de María Leyva (2009) en el cual identifica contextos funerarios conteniendo ofrendas de camélidos al norte de las Lomas de Lachay.

Con respecto a los contextos funerarios Chancay del Horizonte Tardío (dentro del Tawantinsuyu), existe más escaza información. Miguel Cornejo (1991: 110112), a partir del análisis de los contextos funerarios de Lauri, identifica la fase 3B, correspondiente al Horizonte Tardío, caracterizada por presentar estructuras funerarias bastante profundas y de planta cuadrangular, con sección trapezoidal, con el fardo rectangular colocado contra la pared este u oeste y con las ofrendas alrededor del fardo. Cornejo señala que esta fase no presenta ninguna influencia inca, por lo que correspondería a la cultura Chancay dentro del Tawantinsuyu.

Los pocos autores que han estudiado las características de la ocupación Inca en el valle de Chancay y el vecino valle de Huaura llegan a la conclusión de la poca presencia de materiales Inca en la ocupación del Horizonte Tardío en estos valles, mientras que la cerámica Chancay Negro sobre Blanco sobrevive y sigue desarrollándose durante la dominación Inca (Cárdenas, 1977: 24, Kroeber; 1926: 270, Kauffmann; 1973: 437, Jiménez; 1982: 26, van Dalen; 2011a, 2016a: 349-354). Las investigaciones arqueológicas y etnohistóricas referidas a este territorio no indican que los Incas fundaran en estos valles ningún pueblo o centro administrativo (Krzanowski; 1991a: 189). Por su parte, Hans Horkheimer (1970: 376), identificó de la gran cantidad de sitios arqueológicos de la cultura Chancay en el valle Chancay, solo un cementerio con algunos ejemplares de cerámica Inca, sin señalar el nombre del sitio y concluyendo que la influencia Incaica en el valle Chancay es mínima.

Andrzej Krzanowski (1991a) señala la existencia de un sitio en el valle medio de Huaura, conocido como Quintay, el cual identificó en el sector A que el 20\% del total de fragmentería en superficie, proviene de vasijas de uso diario de formas típicas de la cerámica Inca como arybalos y mankas: bordes fuertemente evertidos, bases cónicas, protuberancias en el cuerpo, cuerpos engobados en rojo y labios pintados en rojo. Por su parte en el sector B identificó un área funeraria con tumbas saqueadas y conteniendo en los alrededores algunos restos de cerámica Inca local e Inca-Cuzco. Krzanowski también hace referencia a dos vasijas de estilo Inca Imperial (denominado por el autor como Inca-Cuzco), que se encuentran en la colección del 
Museo Amano y que proceden de los sitios de Lauri y Pampa Hermosa en el valle Chancay; así como dos arybalos Inca Provincial procedentes de Pisquillo Chico; dos vasijas de estilo Chimú-Inca procedentes de Lauri y dos vasijas arybaloides Inca local o ChancayInca procedentes de Chacaca en el valle de Huaura y de Lauri. Para Krzanowski (Ibid: 180) es muy posible el hecho que la mayoría de asentamientos Chancay del Intermedio Tardío siguieron siendo habitados durante el Tawantinsuyu, puesto que el valle Chancay estaba altamente poblado al momento de la invasión hispana, tal como lo describieron los primeros españoles que cruzaron el valle Chancay hacia fines de enero de 1533; sin embargo, la poca densidad de materiales Inca en el valle reflejaría el hecho de la débil influencia incaica en la región.

Esta situación identificada en los valles bajos de Chancay y Huaura es contraria para las cuencas altas. En la subcuenca del río Cayash, en la cuenca alta del río Huaura, Krzanowski (1986: 138-161) identificó cerámica incaica en casi el 50\% de los sitios arqueológicos tardíos (cultura Cayash). Esta cerámica inca está clasificada en cerámica incaica imperial (Inka-Cuzco), conformada por arybalos, mankas y fragmentos diversos; así como cerámica Inca local (Inka-Cayask), conformada también por arybalos con y sin pintura, mankas, ollas, cuencos y diversos. De igual manera, en la cuenca alta del río Chancay, en sitios Atavillos ha sido posible identificar cerámica Inca y conjuntos arquitectónicos en estilo Inca local en Purunmarca (van Dalen; 2016); mientras que en el sitio de Chiprac se ha identificado un Kullpi con vano en doble jamba trapezoidal en el barrio 1, y otros recintos con vanos trapezoidales en el mismo sector, al igual que el vano con doble jamba en la estructura 3C de Añay (Cáceda; 2005: 43); así como la presencia de elementos incaicos en el sitio Iguarí de Chuquimarca (van Dalen; 2011b). Por su parte, en el sitio de Rupac se halló edificios construidos en arquitectura Inca local, como el caso del cabildo y las kallankas, los cuales incluyen elementos arquitectónicos incas, con presencia de fragmentería cerámica Inca local al interior (van Dalen, Grados, Medina y Malpartida; 2016: 452-453).

En el caso específico de Lumbra, a partir de las evidencias arqueológicas se nota claramente que luego de la anexión e inclusión del territorio de la cultura Chancay al Tawantinsuyu como una nación conformante del Chinchaysuyu, y en especial el valle medio del río Chancay-Huaral, el sector B del complejo arqueológico de Lumbra sufrió modificaciones sustanciales en su configuración espacial, lo cual no sucede en el caso del sector A. Estas modificaciones fueron hechas por la población local bajo mandato de las autoridades Inca (van Dalen; 2016a: 351). Durante el Horizonte Tardío, con la llegada del Tawantinsuyu al valle, se nota una gran variación en la organización espacial del sector. Las edificaciones ubicadas hacia el oeste del cuadrilátero fueron desmanteladas a fin de conformar una extensa plaza cuadrangular, asociada a dos kanchas contiguas hacia el lado norte y un pequeño ushnu hacia el lado sur. La modificación sustancial en este sector durante el Horizonte Tardío se debe al simbolismo de control de las entidades religiosas locales, primero de encerrar el área ceremonial con un cuadrilátero de tapiales, como es la plataforma elevada, a la cual se le dio mayor elevación con arquitectura de tapiales, así como también la ampliación hacia el lado noroeste y edificación de recintos de planta cuadrangular a base de tapiales. Esta situación asemeja a lo sucedido en el templo del sol de Pachacámac. Luego, el área fue encerrada en el cuadrilátero.

Los edificios Tawantinsuyu que evidencian la presencia de este estado en el complejo arqueológico de Lumbra, se ubican en el sector B y fueron edificados luego de la anexión de este territorio al Chinchaysuyu. Los edificios Tawantinsuyu presentan la organización y distribución formal del Tawantinsuyu, pero la técnica arquitectónica es local, su construcción fue organizada por el estado, pero los constructores fueron locales; esto además de que los materiales recuperados indican que en el complejo arqueológico de Lumbra no hubo mitqmas durante el Horizonte Tardío.

Con respecto al ushnu, es una estructura arquitectónica característica del Tawantinsuyu, conformada por una o más plataformas superpuestas (van Dalen; 2016a: 355-360), emplazada en el área nuclear de los asentamientos administrativos o en espacios abiertos en orientación a los apus tutelares (como en el caso de los ushnus de Ayacucho, Cavero; 2010). Los ushnus de mayor complejidad y dimensiones se encontraban en el Cusco. Sobre su funcionalidad, Monteverde (2011), propone que era ceremonial, siendo las áreas donde se desarrollaban ofrendas y libaciones de líquidos en honor a las divinidades. El ushnu de mayor importancia en el imperio, habría sido el de la plaza de Haucaypata, 
en medio de la actual ciudad del Cusco. Monteverde (Ibíd: 46-48), precisa que la ubicación de los ushnus en los centros administrativos siempre se asocia a una plaza, ubicándose hacia uno de los lados internos de esta, o en el centro; existiendo vanos de acceso, escalinatas o rampas de acceso desde la plaza hacia la parte superior de la plataforma. Siempre la planta de los ushnus es trapezoidal, rectangular o cuadrangular, existiendo algunos ushnus (como en el caso del sitio arqueológico de Incahuasi en el valle medio del río Cañete en Lunahuaná y en el sitio arqueológico de Aypate en Ayabaca, Piura), que tienen una altura que no supera 1 metro. En cuanto a su técnica constructiva se puede encontrar de finos aparejos en sillería como en Vilcashuamán, sillares rústicos como en Huánuco Pampa, o muros de piedra semicanteada en pircado simple como en Pumpu. El caso del ushnu de Lumbra es similar en sus dimensiones a los ushnus de Incahuasi en Cañete y de Aypate en Piura; mientras que se asemeja en su técnica constructiva con el ushnu de Pumpu. El ushnu de Lumbra se encuentra ubicado al interior del espacio delimitado de la plaza del sector B, la única plaza ubicada al interior del complejo arqueológico de Lumbra, accediéndose a la parte superior a través de una rampa lateral proveniente desde la plaza misma (van Dalen; 2006a: 355-360).

En la costa central hay pocos casos de ushnus, entre estos tenemos: Pachacamac en el valle de Lurín, Huaycán de Pariachi en el valle del Rímac, Piedra Angosta en el valle de Mala, Incahuasi en el valle

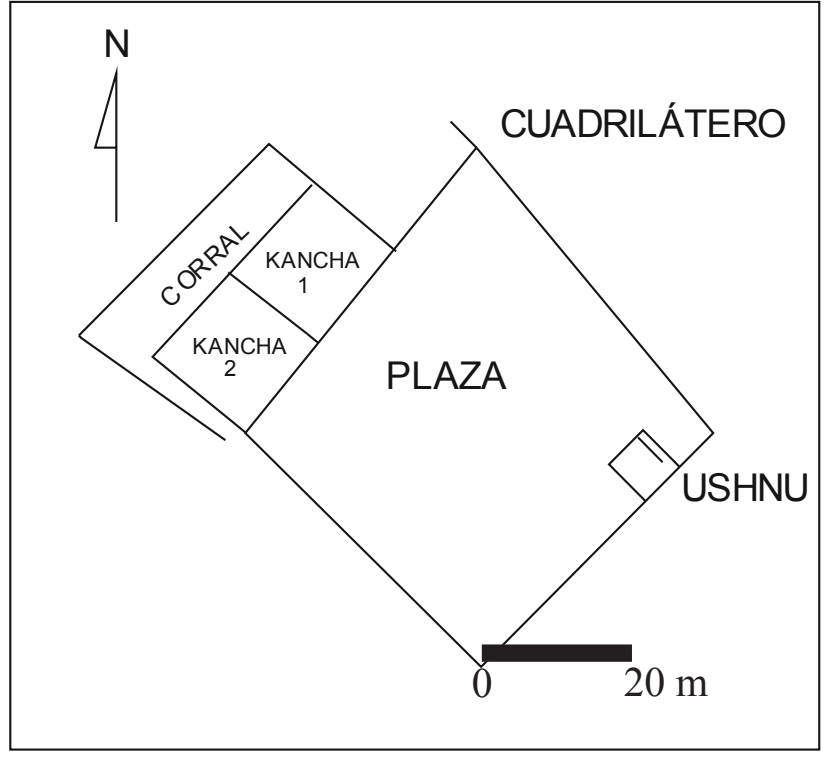

Figura 19: Ubicación del ushnu de Lumbra con respecto a la plaza y a las dos kanchas, Sector B. de Cañete, Tambo Colorado en el valle de Pisco, entre otros. Estos ushnus, salvo los de Pachacamac y Tambo Colorado, son de reducidas dimensiones como el ushnu de Lumbra, y más están representando a esta área ceremonial que cumplir tal función (Ibíd: 359-360).

Las investigaciones desarrolladas en diferentes temporadas (2008, 2012-2013, 2014) en el complejo arqueológico de Lumbra no ha identificado presencia de grupos foráneos o mitqmas, como tampoco se ha podido identificar conjuntos arquitectónicos elaborados en tecnología foránea, ni estilos cerámicos extranjeros, aparte de la cerámica Inca identificada en poca proporción.

Krzanowski (1991a) señala que los pueblos del Intermedio Tardío del valle Chancay siguieron siendo ocupados durante el Tawantinsuyu, sin ser despoblados, siendo las evidencias arqueológicas de la presencia Incaica en el valle realmente escasas, salvo algunos pocos ejemplares del estilo Inca local. Jiménez Borja (1982: 26) seńaló que la cerámica de Estilo Chancay sobrevive a la dominación Inca y pervive hasta la invasión hispana. En el valle bajo y medio del río Chancay no existen evidencia de que los Incas hayan construido un centro administrativo para controlar a la población local, como sí se observa en otros valles de la Costa Peruana. Tampoco se ha identificado asentamientos Chancay que con la anexión de estos territorios al Tawantinsuyu hayan sufrido notables modificaciones en su organización espacial, salvo el sitio de Cuyo dónde, el sector B va a ser encerrado en un cuadrilátero de tapiales, muy similar a lo sucedido en el sector B de Lumbra. En este sentido, no hay evidencias de una ocupación intensiva del valle por agentes estatales cuzqueños.

Lumbra fue el asentamiento Chancay de mayor complejidad espacial durante el Intermedio Tardío en el valle medio del río Chancay; y por lo tanto el más importante de esta zona. Por ello, era lógico que al ser anexado el valle Chancay-Huaral al Tawantinsuyu, sea considerado como un asentamiento administrativo local, para controlar a la población local. La importancia de Lumbra radicaba en su ubicación y su asociación directa al camino de penetración, vía de comunicación con las sociedades de la cuenca alta del río Chancay (Atavillos, Iguari, Vilcas, Pacaybamba) o del Altiplano de Junín (Chinchaycocha).

De los ocho sectores del complejo arqueológico, los más importantes son los sectores A y $\mathrm{B}$, los cuales 
han sido donde hemos realizado investigaciones más intensivas. En el sector A (doméstico), no existe evidencia de cambios sustanciales en la organización de los conjuntos habitacionales, es decir la población siguió viviendo a la usanza y costumbre «antigua», es decir como lo hacían en su etapa independiente (Intermedio Tardío). Esto significa que siguieron desarrollando sus patrones constructivos, siguieron elaborando su misma cerámica, sus mismos tejidos, con los mismos motivos iconográficos propios de su cultura (Estilo Chancay). Siguieron desarrollando las mismas actividades de subsistencia, principalmente la agricultura, cosechando los mismos productos que antaño e intercambiando productos con los ayllus del litoral. Sin embargo, en el sector B (político administrativo), se va a reacondicionar los espacios públicos y ceremoniales, mediante la ampliación (en dimensiones y elevación) de la plataforma con rampa; así como la construcción de un cuadrilátero a base de tapiales que va a encerrar este edificio y los recintos contiguos de función residencial. De igual manera se va a construir conjuntos arquitectónicos que son característicos del Tawantinsuyu, como son las dos kanchas contiguas y el ushnu, asociados a una plaza; aunque la técnica constructiva de estos conjuntos es con técnica local: Chancay. Se buscaba simbólicamente representar conjuntos arquitectónicos del estado imperial, a fin de recordar a los gobernantes y a la población local que estaban dominados por los cuzqueños (van Dalen; 2016a).

Los individuos recuperados en los contextos funerarios de la unidad de excavación junto al ushnu, fueron enterrados durante el Horizonte Tardío y son individuos locales, de la sociedad Chancay, que vivieron en Lumbra durante el Tawantinsuyu. Los estudios forenses determinaron que el individuo masculino no fue sacrificado, murió por Tuberculosis (enfermedad que destruyó sus pulmones); mientras que la mujer murió por un fuerte golpe a la cabeza tras haber engendrado a cinco neonatos. Sobre las enfermedades que aquejaron a los Chancay, son escasas las investigaciones desarrolladas (van Dalen y Carbonel; 2015, Altamirano y Bueno; 2013), por lo que no podríamos precisar el índice de afectados por la Tuberculosis en esta sociedad. Los individuos murieron a una edad relativamente joven (entre 16 y 22 años). El individuo femenino tuvo cinco hijos, lo que evidencia que las mujeres tenían muchos hijos; pues lo mismo revela el hallazgo de otro contexto funerario de otra mujer que tuvo seis hijos en el mismo sitio de Lumbra, (van Dalen; 2016a: 367). Por la contextura robusta de los individuos, estos habrían sido personas dedicadas a la actividad agrícola; además que se ha recuperado restos botánicos (maíz), tanto al interior del fardo, como en los alrededores. La deposición funeraria en este lugar, no parece haber sido parte de un ritual de sacrificio, pues no presentan materiales asociados, salvo la mujer que presenta un tejido anudado y una aguja de cobre de uso personal; pues habría desarrollado la actividad textil en sus actividades domésticas.

El individuo femenino presenta modelación cefálica del tipo tabular oblicuo con achatamiento de la pared derecha, lo cual es una característica muy difundida entre los grupos tardíos de la Sierra Central, como el caso de los Atavillos, Huarochirí y Yauyos. Las investigaciones desarrolladas en sitios Atavillos como Purunmarca, Rupac y Marca Piche, reportaron una alta frecuencia en este tipo de modelación cefálica (van Dalen; 2016b, van Dalen, Grados, Medina y Malpartida; 2016). Es posible que esta mujer sea Atavillos de nacimiento o haya nacido en la chaupiyunga, territorio de Vilcas. La mujer presentaba, además, hiperostosis porótica, una especie de osteoporosis en los huesos del cráneo, producido por una malnutrición crónica. La hipervascularización, evidente en los restos óseos de la mujer, debido al engrosamiento de las arterias, evidencia que tenía algún problema cardiaco.

Los individuos presentaron escasos materiales asociados y todos al interior del fardo. Los materiales asociados al hombre son: un hueso de cuy, un hueso de camélido, dos fragmentos de estilo Chancay-Inca o Inca local; por su parte la mujer presentaba un textil anudado y una aguja de cobre, debido a que realizaría la actividad textil. Alfredo Altamirano (comunicación personal), plantea que la aguja sería un soqawaira, instrumento utilizado por el individuo en su camino hacia el mundo o pueblo de los muertos, utilizado para luchar con los wamanis y apus. La escasez de objetos asociados indica que los individuos corresponden a un bajo estatus en la sociedad Chancay local del Horizonte Tardío; pues el cementerio de Quipullín, ubicado en la otra margen del río Chancay, frente a Lumbra, presenta contextos funerarios Chancay que contienen numerosos objetos asociados (en especial vasijas de Estilo Chancay o Estilo Llano y algunas vasijas Inca local), como se aprecia en los restos disturbados de superficie. 


\section{Conclusiones}

Se ha presentado las características de dos contextos funerarios de la cultura Chancay, enterrados en momentos finales del Horizonte Tardío, asociados al ushnu en el sector B del complejo arqueológico de Lumbra. Uno de los contextos funerarios corresponde a un individuo joven masculino que murió de tuberculosis; mientras que el otro individuo joven es femenino, quien murió de un golpe en la cabeza. Los individuos se dedicaban a la agricultura y la mujer sería oriunda de la chaupi yunga o del territorio Atavillos, esto debido a la modelación cefálica de tipo tabular oblicuo con achatamiento de la pared derecha, que presenta.

Durante el Horizonte Tardío el complejo arqueológico de Lumbra se constituyó en el centro administrativo local más importante, como lo fue desde el Intermedio Tardío, por su ubicación en un punto central de donde confluían caminos a diferentes regiones (Atavillos, Ihuarí, Sayán y Pacaybamba). Por este motivo los Incas reacondicionaron y remodelaron el sector B, edificando elementos arquitectónicos incas como el ushnu, las dos kanchas y la plaza; aunque edificados en tecnología local (Chancay).

\section{Reconocimientos}

Un especial reconocimiento al Dr. Alfredo Altamirano Enciso, quien realizó los análisis de los contextos funerarios presentados. De igual manera, un agradecimiento a los arqueólogos que participaron en las investigaciones, al Bach. Juan Narro Alberca, a la Bach. Gaby Pardo Taquiri y al Bach. Carlos Sairitupac Gutiérrez. De igual manera, a los estudiantes Ross Mery Cuyuchi, Elizabeth Farfán Cayllahua, Piero garrido Centeno, Kevin Guillermo Maguiño, Alex Obregón Neyra, Elio Pérez Peralta y Verónica Rosales Hilario. Un agradecimiento al Vicerrectorado de Investigación de la Universidad Nacional Mayor de San Marcos, que financió los trabajos de investigación a través de los proyectos Multidisciplinarios de investigación. De igual manera, al Lic. Yuri Cavero Palomino por el apoyo para el desarrollo de la investigación.

\section{Referencias bibliográficas}

Agurto Calvo, Santiago y Alfredo Sandoval (1974). Inventario, catastro y delimitación del patrimonio arqueológico del valle del río Chancay. Lima: Instituto Nacional de Cultura. Manuscrito.

Altamirano Enciso, Alfredo y Bueno Mendoza, Alberto (2013). «Un caso de cáncer metastásico en Zapallal a fines del Horizonte Medio (1100-1200 d. C.), valle del Chillón, Perú». En: Investigaciones Sociales, No 30. Lima: Instituto de Investigaciones Histórico Sociales. Facultad de Ciencias Sociales. Universidad Nacional Mayor de San Marcos. pp. 91-104.

CÁCedA Guillén, Daniel (2005). «Determinación arqueológica de las características culturales en los sitios de Chiprac, Rupac, Añay y Cerro Mango». En: Kullpi. Investigaciones culturales en la provincia de Huaral y el Norte Chico. No 2. Huaral, pp. 23-51.

Cárdenas Martín, Mercedes (1977). Informe preliminar del trabajo de campo en el valle de Huaura, departamento de Lima. Lima: Pontificia Universidad Católica del Perú. Instituto Riva-Agüero, Seminario de Arqueología. 74 pp.

Cavero Palomino, Yuri (2010). Inkapamisan: Ushnus y santuiarios Inka en Ayacucho. Huamanga, 139 pp.

Cornejo Guerrero, Miguel (1985). Análisis del material cerámico excavado por Hans Horkheimer en 1961, Lauri, valle de Chancay. Memoria para optar al grado de Bachiller (Tesis). Lima: PUCP, Facultad de Letras y Ciencias Humanas.

Cornejo Guerrero, Miguel (1991). «Patrones Funerarios y discusión cronológica en Lauri, valle de Chancay». En: Estudios sobre la cultura Chancay, Perú. Krakow, Polonia. pp. 83-113.

Cornejo Guerrero, Miguel (1992). «Cronología y costumbres sepulcrales en Lauri, valle de Chancay». En: Estudios de arqueología peruana. D. Bonavía ed., Fomciencias, Lima, pp. 311-354.

Cornejo Guerrero, Miguel (1999). «La sociedad Prehispánica Chancay a través de la muerte». En: Boletín de Lima_No 118, Año 21. Lima: Ed. Los Pinos. pp. 2744. Republicado en: Sequilao. Revista de Historia, Arte y Sociedad. Ańo VIII, No 13, 2001. Lima, pp. 31-50

Engel, Fréderic (1987). De las begonias al maiz: vida $y$ producción en el antiguo Perú. Lima: Centro de Investigaciones de Zonas Áridas. Universidad Nacional Agraria.

Fung Pineda, Rosa (1960). «Huaral: Inventario de una tumba saqueada». En: Etnología y arqueología. Año 1, № 1. Lima, pp 74-129. 
HorkHeimer, Hans (1965). «Identificación y bibliografía de importantes sitios prehispánicos del Perú». En: Arqueológicas No 8 M.N.A.A.H.P. Lima, 70 pp.

Horkheimer, Hans. «Chancay prehispánico: Diversidad y belleza». En: 100 años de arqueología en el Perú. Ravines, comp. Lima: Petroperú. pp. 363-378.

JimÉnez BorJa, Arturo (1982). «Introducción a la cultura Chancay». En: José Lavalle y Werner Lang, editores. Culturas precolombinas: Chancay. Colección de arte y tesoros del Perú. Lima: Banco de Crédito. pp. 9-48.

Kauffmann Doig, Federico (1973). Manual de Arqueología Peruana. Lima: Ediciones PEISA. 636 pp.

Kaulicke, Peter (). Patrones funerarios en Ancón. Lima: Fondo Editorial Universidad Católica. 150 pp.

Kroeber, Alfred Louis (1926). «The Uhle pottery collections from Chancay». En: Publications in American Archaeology and Ethnology. Vol. 21, No 7. University of California. Berkeley, pp. 265-304.

Krzanowski, Andrzej (1986). Cayash Prehispánico; primera parte del informe sobre las investigaciones arqueológicas de la Expedición Científica Polaca a los Andes. Proyecto Huaura-Checras (Perú 1978). Polska Akademia Nauk. Prace Komisji Archeologicznej No 25. Cracovia, Polonia, 277 pp.

KrZANowski, Andrzej (1991). «Influencia inca en los valles de Huaura y Chancay». En: Estudios sobre la cultura Chancay-Perú. Krakow, pp. 189-214.

KrZanowski, Andrzej (2008). Kultura Chancay. Srodkowe wybrzeze Peru. Krakow, 225 pp.

Leyva Velasco, María Ysela (2009). Ritos de fertilidad, evidencia de camélidos en la costa central. Tesis para optar el título profesional de Licenciado en Arqueología. Lima: Facultad de Ciencias Sociales, Universidad Nacional Mayor de San Marcos. 168 pp.

Monteverde Sotil, Luis (2011). «La configuración arquitectónica de los ushnus como espacios de libaciones y ofrendas líquidas durante el Tahuantinsuyo». En: Bulletin de l'Institut français d'études andines. No 40 (1). Lima, pp. 31-80.

Tello, Julio C. (2015). Cuadernos de Investigación del Archivo Tello, No 11: Arqueología del territorio Chancay. Lima: Museo de Arqueología y Antropología, Universidad Nacional Mayor de San Marcos. 138 pp.

VAn Dalen Luna, Pieter (2004a). «Arqueología y Etnohistoria de los Periodos Tardíos en la provincia de Huaral». En: Revista del Centro de Estudiantes de Arqueología. Lima: Universidad Nacional Mayor de San Marcos, 2004. pp. 22-48.
Van Dalen Luna, Pieter (2004b). «Los valles de Chancay y Huaura dentro del Tahuantinsuyo». En: Boletín del Patronato de defensa del Patrimonio cultural de los valles de Huaura y Ambar. $\mathrm{N}^{\circ} 16$. Huacho, pp. 2-8.

Van Dalen Luna, Pieter (2008). Los ecosistemas arqueológicos en la cuenca baja del río Chancay-Huaral. Su importancia para el desarrollo de las formaciones sociales prehispánicas. Lima: Ed. Gutemberg. 185 pp.

Van Dalen Luna, Pieter (2009). «Sistemas de asentamiento en el valle medio del río Chancay». En: Kullpi. Investigaciones culturales en la provincia de Huaral y el Norte Chico. Año 4, No 4. Lima, pp. 217-294.

Van Dalen Luna, Pieter (2010a). «Análisis de un documento de extirpación de idolatrías procedente del complejo arqueológico Lumbra, valle medio del río ChancayHuaral». En: Investigaciones Sociales, No 24. Lima: Instituto de Investigaciones Histórico Sociales. Facultad de Ciencias Sociales. Universidad Nacional Mayor de San Marcos. pp. 85-105.

Van Dalen Luna, Pieter (2010b). "Investigaciones Arqueológicas en Hualmay, valle de Huaura». En: Guara. No 8. Museo Arqueológico de la UNJFSC. Huacho, pp. 15-27.

Van Dalen Luna, Pieter (2011a). «El Tawantinsuyu en la costa norcentral peruana: valles de Chancay y Huaura». En: Investigaciones Sociales, No 27. Lima: Instituto de Investigaciones Histórico Sociales. Facultad de Ciencias Sociales. Universidad Nacional Mayor de San Marcos. pp. 77-104.

Van Dalen Luna, Pieter (2011b). Arqueología e historia temprana de la Comunidad Campesina de Huachinga, distrito de Ihuarí, Huaral. Lima: Ed Gutemberg. 2011. $68 \mathrm{pp}$.

Van Dalen Luna, Pieter (2012). "Análisis arquitectónico y secuencias de ocupación en el sitio de Pampa de Ánimas La Wasa, Luriama, Campiña de Santa María, valle de Huaura». En: Kullpi. Investigaciones culturales en la provincia de Huaral y el Norte Chico. Año 6, No 6. Lima, pp. 67-118.

Van Dalen Luna, Pieter (2013a). «Arqueología tardía del valle Chancay-Huaral: identificando la nación Chancay». En: Investigaciones sociales. $\mathrm{N}^{\circ}$ 28. Lima: Instituto de Investigaciones Sociales, Facultad de Ciencias Sociales. Universidad Nacional Mayor de San Marcos. pp. 271-284

Van Dalen Luna, Pieter (2013b). «Investigaciones en el complejo arqueológico de Lumbra, un asentamiento tardío del valle medio del río Chancay-Huaral». En: 
Investigaciones sociales. $\mathrm{N}^{\circ}$ 28. Lima: Instituto de Investigaciones Sociales, Facultad de Ciencias Sociales. Universidad Nacional Mayor de San Marcos. pp. 285-302.

Van Dalen Luna, Pieter (2013c). «Contextos funerarios Chancay en Macatón, valle Chancay-Huaral». En: Arqueología y Sociedad, $\mathrm{N}^{\circ}$ 25. Lima: Museo de Arqueología y Antropología, Universidad Nacional Mayor de San Marcos. 2012. pp. 259-302.

Van Dalen Luna, Pieter (2014a). «El Periodo de Transición Tawantinsuyu-Colonial o de desestructuración andina en el complejo arqueológico de Lumbra, valle medio del río Chancay-Huaral». En: Lima subterránea. Arqueología histórica: criptas, bóvedas, canales virreinales y republicanos. Lima: Universidad Nacional Mayor de San Marcos. pp. 29-56.

Van Dalen Luna, Pieter (2014b). "Las plataformas con rampa de la cultura Chancay». En: Kullpi. Investigaciones culturales en la provincia de Huaral y el Norte Chico. Año 7, No 7. Lima, pp. 25-78.

Van Dalen Luna, Pieter (2016a). Estrategias de dominación Tawantinsuyu en el complejo arqueológico de Lumbra, valle medio del río Chancay, provincia de Huaral. Lima: Tesis para optar el grado de Magíster en Arqueología Andina. Universidad Nacional Mayor de San Marcos. 432 pp.

Van Dalen Luna, Pieter (2016b). "Contextos funerarios Atavillos en Purunmarca, Vichaycocha-Huaral». En: Arqueología y Sociedad. No 30. Lima: Museo de Arqueología y Antropología, Universidad Nacional Mayor de San Marcos. pp. 39-100.

Van Dalen Luna, Pieter (2016b). La provincia de Huaral en la historia. Lima: Ed. Gutemberg. 142 pp.

Van Dalen Luna, Pieter (2017). «El hallazgo de un quipucamayoc en Cerro Colorado, Huacho». En: Arqueología y Sociedad, $\mathrm{N}^{\circ}$ 31. Lima: Museo de Arqueología y Antropología, Universidad Nacional Mayor de San Marcos. pp. 305-312.

Van Dalen Luna, Pieter; Altamirano Enciso, Alfredo; Grados Rodriguez, Hans y Castillo Valle, Rosario (2013). «Los camélidos de Lumbra, valle medio de
Chancay, Perú». En: Investigaciones sociales. No 33. Lima: Facultad de Ciencias Sociales, Universidad Nacional Mayor de San Marcos. pp. 87-104.

Van Dalen Luna, Pieter; Carbonel Arana, Dayanna (2015). «Un caso de cordoma óseo (cáncer) en individuo Chancay de Cerro Colorado, Santa María, Huaura». En: Arqueología y Sociedad. No 29. Lima: Museo de Arqueología y Antropología de San Marcos. Universidad Nacional Mayor de San Marcos. pp. 167-182.

Van Dalen Luna, Pieter y Grados Rodríguez, Hans (2014). «Los quipus del complejo arqueológico de Lumbra, Huaral». En: Guara. Revista del Museo de Arqueología de la Universidad Nacional José Faustino Sánchez Carrión. No 18. Huacho, pp. 19-27.

Van Dalen luna, Pieter; Grados Rodríguez, Hans; Medina Sánchez, Francisco y Malpartida Gamarra, Miller (2016). "Conviviendo con los ancestros: investigaciones arqueológicas en Rupac-Huaral». En: Arqueología y Sociedad. No 30. Lima: Museo de Arqueología y Antropología, Universidad Nacional Mayor de San Marcos. pp. 425-472.

Van Dalen luna, Pieter; Grados Rodríguez, Hans; tello CUAdros, Roberto; Vivanco, Iván; Flores Livia, Wendy; y Marcelo Gonzales, Yerovi (2014). «Resultados del proyecto de rescate arqueológico en el área de la parcela 4 y 5 del sitio arqueológico Cerro Colorado, Santa María, provincia de Huaura». En: Kullpi. Investigaciones culturales en la provincia de Huaral y el Norte Chico. Año 7, No 7, Lima, pp. 189-216.

Van Dalen Luna, Pieter; Tello Cuadros, Roberto; Grados Rodríguez, Hans (2015). «Un Contexto funerario del Horizonte Medio procedente de Cerro Colorado, Huacho». En: Arqueología y Sociedad. No 30. Lima: Museo de Arqueología y Antropología de San Marcos. Universidad Nacional Mayor de San Marcos. pp. 407-424.

Vidal Vidal, Hilda (1969). Excavaciones arqueológicas en Pasamayo. Lima: Patronato y Museo de sitio de Ancón.

Villar Córdova, Pedro (1982 [1935]) Arqueología del departamento de Lima. Lima: Ed. Atusparia, 424 pp. 